\title{
Kernos
}

Revue internationale et pluridisciplinaire de religion grecque antique

29 | 2016

Varia

\section{Rois éphémères. Enquête sur le sacrifice humain}

\section{Pierre Bonnechere}

\section{CpenEdition \\ Journals}

\section{Édition électronique}

URL : http://journals.openedition.org/kernos/2450

DOI : 10.4000/kernos.2450

ISSN : 2034-7871

\section{Éditeur}

Centre international d'étude de la religion grecque antique

\section{Édition imprimée}

Date de publication : 1 octobre 2016

Pagination : 470-471

ISSN : 0776-3824

Référence électronique

Pierre Bonnechere, «Rois éphémères. Enquête sur le sacrifice humain », Kernos [En ligne], 29 | 2016, mis en ligne le 01 octobre 2016, consulté le 18 novembre 2020. URL : http://journals.openedition.org/ kernos/2450 ; DOI : https://doi.org/10.4000/kernos.2450

Ce document a été généré automatiquement le 18 novembre 2020.

Kernos 


\title{
Rois éphémères. Enquête sur le sacrifice humain
}

\author{
Pierre Bonnechere
}

\section{RÉFÉRENCE}

Francesca PRESCENDI, Rois éphémères. Enquête sur le sacrifice humain, Genève, Labor et Fides, 2015. 1 vol. $15 \times 22,5 \mathrm{~cm}, 198$ p. ISBN : 978-2-8309-1500-6.

1 Le dernier livre de F. Prescendi est placé sous l'étoile d'Agatha Christie. Un fait divers à Dijon, en décembre 1951 : l'effigie du Père Noël a été pendue puis brûlée sur le parvis de la cathédrale, en réaction à la commercialisation d'une fête qui risquait de perdre, peu à peu, son message religieux plus profond. Claude Lévi-Strauss, dès 1952, publia un article puissant où il incluait ce pauvre Père Noël à la longue liste des rois éphémères que diverses traditions érigent en potentats d'un jour ou quelques mois, pour ensuite les éliminer (parfois par sacrifice ou auto-sacrifice). Le plus célèbre d'entre eux, pour les antiquistes, est le " roi des Saturnales ", maître temporaire d'une période de licence avant le retour à l'ordre. Lévi-Strauss se fonde sur la magistrale dernière édition du Rameau d'or de James Frazer. L'ombre d'Hercule Poirot se faufile quand F.P. se met à creuser la genèse de ce texte fondateur et toujours attractif (chap. 2-3). Le spectre du sacrifice humain plane sur ces sombres histoires de Saturne/Cronos, dont on sait le côté ambivalent. Or Frazer se fonde sur la découverte alors toute récente (1896), à la Bibliothèque Nationale de Paris par Franz Cumont, des Actes de saint Dasius, martyr en 303 lors des grandes persécutions de Dioclétien. Cette passion, écrite en latin mais connue seulement par une traduction grecque, peut-être $d u v^{e}$ ou du $v^{e}$ s. ap. J.-C., raconte la fin tragique d'un soldat chrétien caserné en Mésie, qui aurait préféré mourir sans délai plutôt que de subir un mois durant le rôle - très païen - de roi des Saturnales, lequel devait se suicider d'un coup de couteau sacrificiel (dans un acte de devotio). En soi d'importance secondaire, l'histoire de Dasius est instrumentalisée par Frazer, dans l'édition revue de 1900, pour justifier une lecture - très osée pour l'époque - de la passion du Christ à la lumière des traditions du « roi des Saturnales » 
ou plus exactement à la lumière d'une tradition juive de ce type, les Pourim. L'enquête se nourrit ici des écrits de l'époque, comme ceux de Paul Wendland, et surtout de la correspondance entre Franz Cumont et ses homologues James Frazer, Léon Parmentier et Andrew Lang. On découvre, surpris (mais l'est-on vraiment, et faisons-nous différemment aujourd'hui ?), comment le Zeitgeist finit souvent par avoir raison des réserves méthodologiques qui, au début, garantissent l'interprétation des auteurs. Cumont avait fait preuve, dans l'édition des Actes, d'une prudence parfaite (très actuelle en fait), avant d'être converti, selon ses propres termes, par les arguments de Léon Parmentier, arguments que Parmentier lui-même jugeait pourtant faibles et audacieux : il en parlait même, avec beaucoup d'ironie, comme d'une

« $\mathrm{C}[\mathrm{r}]$ onerie » qu'il envisageait froidement de ne pas publier. La machine s'emballe alors, en dépit de l'opposition d'Andrew Lang, et le récit de Dasius est promu pierre de touche essentielle à l'historicité des sacrifices humains dans les rites brumeux du Saturne originel jusque tard sous l'empire. Malgré toutes les tentatives officielles pour enrayer ces pratiques répréhensibles, il aurait donc toujours existé des poches de résistance, aux marges du pouvoir, qui auraient fini par ressurgir, comme dans les campements d'une armée attardée, au cœur d'un monde profondément troublé, dans la « lointaine » Mésie.

2 À cet égard, les tentatives des meilleurs spécialistes pour prouver l'existence du sacrifice humain dans le monde antique demeurent étonnamment proches des arguments antiques, glosant sur les attaques chrétiennes et supputant sur la possible historicité des faits faute de pouvoir les prouver nuls et non avenus. Il reste surprenant aussi que, pour asseoir leur pensée, ils se soient acharnés à démontrer l'existence de ce sacrifice humain à partir de coutumes qui étaient censées être celles de peuples périphériques, comme les Scythes (Saces), les Babyloniens (ou les Perses) ou encore les Albanoi du Caucase. En quoi, logiquement, ces coutumes étrangères, et tellement étrangères qu'elles ont souvent servi de repoussoir, auraient-elles pu éclairer la religion romaine archaïque? Le comparatisme entre cultures est fascinant, mais il ne peut donner lieu à un jeu d'analogies qui permettrait de reconstruire une réalité mal connue ici avec des éléments provenant d'ailleurs et soi-disant mieux connus. Quant aux rares parallèles gréco-romains, d'un hypothétique sacrifice à Cronos sur l'île de Rhodes à quelques histoires de pharmakoi (dont la mise à mort est déniée dans la plupart des sources plus anciennes), aucun ne correspond de prime abord au canevas $\mathrm{du}$ « roi des Saturnales », et il faut en mélanger les données pour les faire ressembler à l'image qu'on veut en obtenir a priori. Les sources qui en font mention posent d'énormes problèmes de critique historique, notamment en fonction de leur finalité (philosophique ou apologétique), ou encore de leur qualité très discutable, comme des scholies tardives qui contredisent des textes plus anciens et en général plus avisés. F.P., trop prudente même par endroit, dépeint un tableau très judicieux de l'état de la recherche actuelle sur chacun de ces parallèles (chap. 4).

3 Laissant donc de côté toute conclusion qui serait abusive au regard des sources dont nous disposons, F.P. tire les enseignements possibles de son enquête: le sacrifice du martyre de Dasius ne peut être généralisé aux Saturnales et moins encore dans tout l'empire. C'est donc un « cadavre » qui disparaît du placard de la religion antique, une élimination dont profitera l'étude de la fête des Saturnales dans le cadre de la religion romaine. Le meilleur du travail réside cependant, à mes yeux, dans l'approche historiographique : aux alentours de 1900 s'élaborent les grands courants interprétatifs 
de la religion ancienne. Concernant le sacrifice humain, deux tendances s'y sont opposées (et s'opposent toujours d'ailleurs) entre ceux qui ne pouvaient admettre que leurs ancêtres culturels aient été des barbares, et ceux qui prétendaient ramener les Grecs et les Romains à une vision évolutionniste et leur découvrir des comportements moins avouables (la fameuse "Primitive Culture »). À l'époque aussi où l'hagiographie était davantage prise au sérieux pour les faits qu'on y trouvait relatés, les Actes de saint Dasius apparaissaient comme une source acceptable, même s'il fallait la manipuler avec grand soin. Les interprétations antiques reliées au sacrifice, à la devotio, ou encore aux gladiateurs, et bien entendu au Christ et à sa renaissance, sur un fond de fertilité (cf. les Féries), ont servi de terreau aux historiens qui, à l'époque, n'ont que très partiellement échappé aux concepts antiques.

4 En conclusion, un livre qui ne se veut pas exhaustif, mais bien pensé et qui se lit comme un roman. Il n'est pas de mise, évidemment, de critiquer l'attitude de nos devanciers, qui ne disposaient pas de l'arsenal interprétatif complexe dont nous bénéficions aujourd'hui, comme l'histoire des représentations, le comparatisme éclairé ou encore le concept de l'Autre. À rebours, le contre-exemple de ces grands savants doit nous mettre en garde contre nos propres certitudes simplificatrices, ou nos avancées trop audacieuses, dont riront certainement nos successeurs.

\section{AUTEURS}

\section{PIERRE BONNECHERE}

affilié à l'Université d'Uppsala - Université de Montréal 